\title{
Anaphylaxis and anaesthesia
}

\author{
Korda B \\ Department of Anaesthesia, Chris Hani Baragwanath Academic Hospital, University of the Witwatersrand \\ *Corresponding author, email: drbkorda@gmail.com
}

Anaphylaxis is defined as'a severe life-threatening, generalised or systemic hypersensitivity reaction'.1 The recent $6^{\text {th }}$ National Audit Project (NAP6) in the United Kingdom (UK) defined perioperative anaphylaxis as 'anaphylaxis which occurs in patients undergoing a procedure requiring general or regional anaesthesia or sedation or managed anaesthesia care (anaesthesia monitoring only) under the care of an anaesthetist between the period of first administration of a drug (including premedication) and the post-procedure transfer to a ward, or critical care.'. This short narrative review will discuss the recent NAP6 results in the context of current knowledge, as relevant to the South African anaesthetist.

Perioperative anaphylaxis is seen as a rare event, with a reported incidence between 1:1250- 1:20 000 anaesthetics, ${ }^{3}$ equating to on average once every 7 years per anaesthetist. ${ }^{2}$ However, it is one of the more common life-threatening anaesthetic complications, compared to other events such as MH (1:30 000 $100000)^{4}$ or an airway complication $(1: 22000) .{ }^{5}$ The mortality for perioperative anaphylaxis was previously predicted in the range of 3-9\%. ${ }^{6}$ This has not been validated in more recent studies in developed nations which report it as being significantly lower, ranging from $0-4.1 \% .7$

What separates anaphylaxis from many other perioperative critical events is its unpredictable, precipitous but often occult nature. An acute $\mathrm{Ml}$, a bronchospasm in an asthmatic or devastating surgical haemorrhage can be more easily predicted or identified. In contrast, anaphylaxis is likely to strike without warning, and may progress to cardiac arrest in a matter of minutes. ${ }^{2}$ Compounding this is a potential failure to recognise the root cause as anaphylaxis, and therefore fail to institute specific therapy. Furthermore, under-recognition and underdiagnosis means that the patient is at risk during any subsequent procedures. $^{9}$

The majority of anaphylaxis occurs in the community and may present to prehospital emergency services or an emergency department. ${ }^{10}$ However, up to one third of anaphylaxis-related ICU admissions are directly from operating theatres. ${ }^{11}$ This likely reflects the increased severity with which perioperative anaphylaxis presents. Combined with the observation that druginduced anaphylaxis is rising worldwide, ${ }^{10}$ it is easy to see why this disease process warrants special interest from anaesthetic societies.
The recently released NAP6 adds significantly to the body of evidence around perioperative anaphylaxis. It is the latest in a series of service evaluations that examine anaesthesia-related complications, which have been run from 2003 by the UK's Royal College of Anaesthetists (RCoA). The National Audit Projects are prospective, observational cohort studies run nation-wide to examine rare events occurring during anaesthesia, and have thus far looked at complications of neuraxial blockade (NAP3), airway complications (NAP4) and awareness under anaesthesia (NAP5). ${ }^{12}$ NAP6 was released in May 2018 and focused on perioperative anaphylaxis.

In South African medical literature, no data on perioperative anaphylaxis could be found. There seems to be little published evidence regarding causes, clinical features or outcomes. The only local narrative review from the last 10 years was in Current Allergy and Clinical Immunology, the official journal of the Allergy Society of South Africa. ${ }^{13}$ A need for local research on this and other anaesthesia-related topics has already been highlighted by Kluyts et al. in their editorial on the UK's NAP programme. ${ }^{14}$ Until such a time as similarly comprehensive studies become available on African or low-middle income countries (LMIC), there will be continued reliance on international data.

\section{NAP6 Summary ${ }^{2}$}

The NAP6 survey represented a collaborative effort between anaesthesiologists, critical care physicians, allergists and immunologists, involving $100 \%$ of NHS hospitals in the UK. An extensive network of local representatives was set up across the NHS hospitals, each of whom disseminated and gathered information pertaining to perioperative anaphylaxis in their hospitals. Cases were then anonymised and reported online over a year long period. Each case had significant detail regarding the intraoperative progression and management of the suspected anaphylactic event, as well as details of allergy referral follow-up. All the cases received were reviewed, and those deemed to be true cases were included in the final analysis. ${ }^{15}$

Parallel to this major component of the study, several smaller components included the Baseline Survey (anaesthesiologists' perceptions regarding anaphylaxis and its management); the Activity Survey (a month-long study to determine the extent of anaesthetic services provided in NHS hospitals) and the Allergen Survey (detailed survey of allergens that patients were exposed to in the perioperative period). These components were 
administered separately. Ethics was obtained for all of the above aspects of NAP6, and approved at a national and local level. ${ }^{15}$ Data collection was completed in 2017, and the report released in May 2018. The process is summarised in Figure 1.

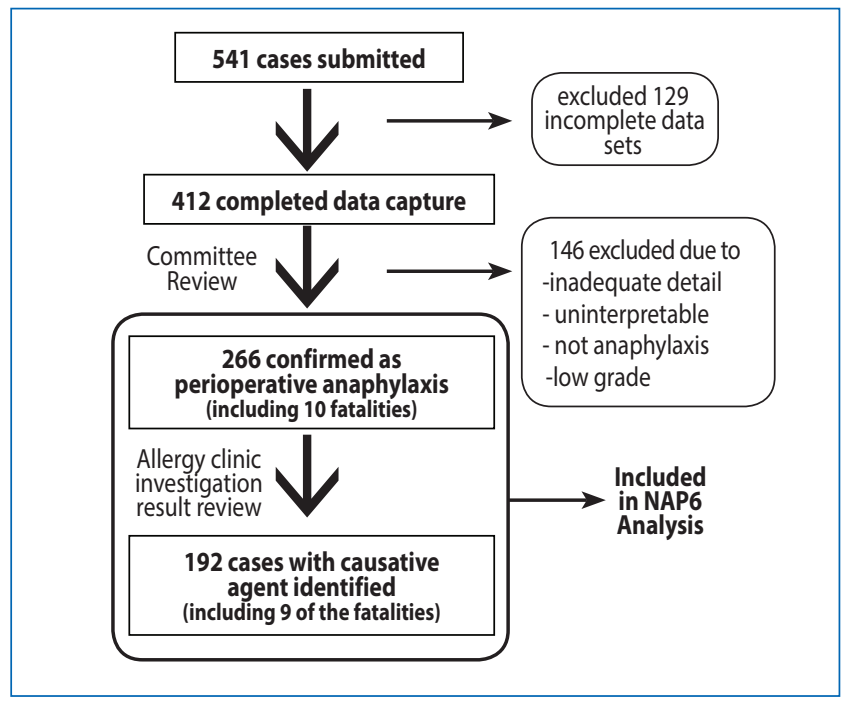

Figure 1: Summary of NAP6 Case Idntification ${ }^{2}$

NAP6 represents the most comprehensive prospective review of perioperative anaphylaxis to date. Certain shortcomings should be kept in mind:

- reliance on individual reporting of suspected cases, with an inherent risk of underreporting and therefore missed cases;

- prominence of the study likely raised awareness of perioperative anaphylaxis for individual practitioners, therefore increasing likelihood of diagnosis - detection rates may therefore be greater than in an 'unprimed' practitioner population outside the UK;

- non-inclusion of a predicted 1.5 million surgeries in the (nonNHS) private sector, representing one third of all surgeries in UK during that period;

- based in high income European nation (UK) therefore potentially limited applicability to LMIC or African countries.

The NAP6 results were published in a 238-page document (available for free at www.nationalauditproject.org.za) and an attempt to summarise all findings and recommendations would be flawed at the outset. Instead, certain aspects will be highlighted throughout the remainder of the article.

\section{Clinical Pathoimmunobiology}

Recent advances in immunology have shed new light on the molecular mechanisms of this incredibly complex entity. Although a clinical focus should remain on the likely triggers, clinical presentation and cornerstones of treatment in the perioperative setting, the need to address potential long-held but false assumptions remains.

Anaphylactoid is Anaphylaxis. Anaphylaxis was previously thought of solely as a Type I hypersensitivity phenomenon. ${ }^{16}$ We now know that although most anaphylaxis has an allergic lgE-mediated mechanism, this is not exclusively the case. ${ }^{17}$
Anaphylaxis is now subdivided into one of four mechanistic pathways - IgE-Dependent Immunological Anaphylaxis, IgEIndependent Immunological Anaphylaxis, Nonimmunological Anaphylaxis and Idiopathic Anaphylaxis. ${ }^{18}$ The older term 'anaphylactoid reaction'has been supplanted by lgE-Independent Anaphylaxis, whilst the direct histamine release causes by drugs such as opioids and the benzylisoquinolone neuromuscular blocking agents (NMBAs) is termed Nonimmunological Anaphylaxis. All these mechanisms are termed anaphylaxis, if potentially life-threatening features develop, and are to be treated as such.

The first anaesthetic isn't 'safe'. Prior sensitisation to drugs is often unnecessary, so the first anaesthetic a patient receives can still result in anaphylaxis to anaesthesia-specific drugs. Firstly, as mentioned above, not all anaphylaxis is allergic, and a particular patient may have a hypersensitivity to certain medications (e.g. morphine) without any prior exposure. ${ }^{19}$ Second, prior exposure in allergic anaphylaxis may occur via a molecule with the same allergenic epitope, as is seen to occur in IgE-dependent NMBAinduced anaphylaxis to rocuronium. In this entity, IgE antibodies are seen to be present prior to the administration of any NMBA. The proposed agents that lead to this prior sensitisation include over-the-counter medications, cosmetics and disinfectants. ${ }^{20}$ Regardless of the underlying mechanism, the practicing anaesthetist should regard the first anaesthetic as a potential anaphylactic risk, regardless of drugs administered.

Anaesthetic 'veterans' are not low-risk. New hypersensitivities may develop over time, whilst a previously subclinical or missed hypersensitivity may manifest in a life-threatening way at a subsequent exposure. ${ }^{18}$ This may be particularly relevant with patients in altered physiological states. In its guidelines, the WAO makes mention of factors that may potentially contribute to severe or life-threatening anaphylaxis, and co-factors that amplify it. These include amongst others: concurrent medication use (specifically ACE-inhibitors and $\beta$-blockers); recent ethanol ingestion; acute infections; premenstrual status; psychiatric illness; and emotional stress. ${ }^{18,21}$ Therefore it can be seen that subsequent anaesthetics always pose a risk for anaphylaxis, even in relatively 'experienced' patients.

The overarching message is that constant vigilance is essential, and adherence to practicalities, such as standard monitoring, in the perioperative period. The clinical history remains crucial in quantifying risks, but is far from full-proof. Perioperative anaphylaxis can occur in any patient, no matter their clinical history.

\section{Aetiological Agents}

The large number of medications received during a generic general anaesthetic means the risks of iatrogenic anaphylaxis increases significantly during the perioperative period. The Allergen Survey component of NAP6 determined that in a general anaesthetic, a median of 8 drugs were administered, ranging up to a maximum of 20.22 Concurrently, identification of the offending agent also becomes difficult in this context. The balance of the evidence is that the highest risk drug 
groups for anaphylaxis are antibiotics and NMBAs. Which group predominates depends on the population analysed. ${ }^{3}$ Other rarer potential triggers are also discussed briefly below.

Epidemiological studies of all-cause perioperative anaphylaxis triggers have dominated the literature over the last decade. Prior to NAP6, a number of retrospective analyses were published that include data from the UK, ${ }^{23}$ France, $^{24}$ the United States ${ }^{25}$ and many others. They are most succinctly summarised in the review by Mertes et al. in $2016 .{ }^{3}$

It must be understood that there is likely to be geographical and temporal variation in the perioperative causes of anaphylaxis. Anaesthetic practice is constantly evolving, with changes in drug preference. Certain drugs are favoured over others, based on prevailing local practices and changes in drug availability. NAP6 highlighted a change in practice in the UK regarding propofol and succinylcholine since NAP5. ${ }^{26}$ Different populations may also have differing susceptibilities to develop hypersensitivity, based on genetic and environmental factors. ${ }^{27}$

The strength of NAP6 as a study lies not only in its prospective nature. The Activity and Allergen Surveys allow quantification of risk for particular drugs based on actual contemporary use. Previously, risk for a particular drug or drug group was based on drug sales, not measured perioperative drug utilisation. For the first time, anaphylactic risk of drug groups and individual drugs could be established. Some of these findings are summarised in Table $1 .{ }^{2}$

\section{Antibiotics}

Antibiotics are oft quoted as the most frequent cause of druginduced anaphylaxis ${ }^{28}$ and perioperative anaphylaxis in the US ${ }^{25}$ and now the UK. ${ }^{2}$ This is in contrast to the comprehensive French data that placed them in third position. ${ }^{24}$ In the NAP6 Allergen study, antibiotics were given in $57 \%$ of all anaesthetics administered, with co-amoxiclav, gentamicin and cefuroxime being the three most frequently administered antibiotics. Antibiotics were implicated in $46 \%$ of perioperative anaphylaxis cases with an identifiable cause and were the most frequently implicated drug group. Co-amoxiclav and teicoplanin were the most commonly implicated individual agents, together constituting $89 \%$ of antibiotic identified as agents. The results as they relate to antibiotic induced anaphylaxis are summarised in Table 2.

Ironically, teicoplanin was associated with use as an alternative in patients giving a history of allergy to penicillin. ${ }^{2}$ In this author's experience, this is rarely the practice in South Africa. Teicoplanin is therefore unlikely to be a similar problem locally, although it should be borne in mind if it becomes an alternative to current second-line antibiotics such as clindamycin.

NAP6 identified cefuroxime as a relatively infrequent cause. It was the only cephalosporin identified as a causative agent, but was also clearly the cephalosporin of choice for perioperative antibiotic prophylaxis, being given in $94 \%$ of cases where a cephalosporin was used. ${ }^{22}$ This probably does not reflect South African practice, and thus may not have relevance. Studies

Table 1: Summary of Activity Survey, Allergen Survey and Perioperative Anaphylaxis Causes in NAP62,22,26

\begin{tabular}{|c|c|c|c|c|c|c|}
\hline Drug Group & $\begin{array}{l}\text { Estimated no of } \\
\text { patients receiving } \\
\text { drug group per } \\
\text { annum }\end{array}$ & $\begin{array}{l}\% \text { of anaesthetics } \\
\text { receiving this } \\
\text { drug group }\end{array}$ & $\begin{array}{c}\text { No of cases of } \\
\text { anaphylaxis as } \\
\text { a result of drug } \\
\text { group }\end{array}$ & $\begin{array}{c}\% \text { of total } \\
\text { anaphylaxis Cases } \\
\text { with identified } \\
\text { cause }\end{array}$ & $\begin{array}{l}\text { Rate of anaphylaxis } \\
\text { from drug group } \\
\text { (per } 100000 \\
\text { administrations) } \\
\text { [Range] }\end{array}$ & $\begin{array}{c}\text { No of Deaths } \\
\text { due to drug } \\
\text { group }\end{array}$ \\
\hline Antibiotics & 1787360 & $57.2 \%$ & 92 & $46 \%$ & $\begin{array}{c}4 \\
{[0.37-16.4]}\end{array}$ & 3 \\
\hline NMBAs & 1129478 & $\begin{array}{c}36.1 \% \\
(47.2 \% \text { of GAs) }\end{array}$ & 65 & $33 \%$ & $\begin{array}{c}\text { Agent-specific } \\
{[3.25-11.1]}\end{array}$ & 4 \\
\hline Chlorhexidine & 2298567 & $73.5 \%$ & 18 & $9.0 \%$ & 0.78 & 1 \\
\hline Patent Blue & 61768 & $2 \%$ & 9 & $4.5 \%$ & 14.6 & 0 \\
\hline Other & & & 13 & $6.5 \%$ & & 1 \\
\hline Unknown & & & 74 & & & 1 \\
\hline $\begin{array}{l}\text { Total no of } \\
\text { anaesthetic cases }\end{array}$ & 3126067 & & $\begin{array}{l}266 \text { total cases } \\
\text { of confirmed } \\
\text { anaphylaxis }\end{array}$ & $\begin{array}{c}72 \% \text { with } \\
\text { identifiable cause } \\
\text { (192) }\end{array}$ & 8.5 & 10 \\
\hline
\end{tabular}

Table 2: Summary of NAP6 results regarding Antibiotics 2,22,26

\begin{tabular}{|c|c|c|c|c|c|c|c|}
\hline Antibiotic & $\begin{array}{c}\text { Estimated no of } \\
\text { patients receiving } \\
\text { antibiotic per annum }\end{array}$ & $\begin{array}{l}\% \text { of all } \\
\text { cases }\end{array}$ & $\begin{array}{c}\% \text { of all } \\
\text { cases } \\
\text { receiving } \\
\text { antibiotics }\end{array}$ & $\begin{array}{c}\text { No of cases of } \\
\text { anaphylaxis }\end{array}$ & $\begin{array}{c}\% \text { of total } \\
\text { anaphylaxis cases } \\
\text { with identified } \\
\text { cause }\end{array}$ & $\begin{array}{l}\text { Rate of anaphylaxis } \\
\text { (per } 100000 \\
\text { administrations) }\end{array}$ & $\begin{array}{c}\text { No of } \\
\text { Deaths }\end{array}$ \\
\hline All Antibiotics & 1787360 & $57.2 \%$ & $100 \%$ & 92 & $46 \%$ & 4 & 3 \\
\hline Co-amoxiclav & 532,580 & $17.0 \%$ & $29.8 \%$ & 46 & $23 \%$ & 8.7 & 1 \\
\hline Teicoplanin & 219621 & $7.0 \%$ & $12.3 \%$ & 36 & $18 \%$ & 16.4 & 2 \\
\hline Cefuroxime & 424143 & $13.6 \%$ & $23.7 \%$ & 4 & $2 \%$ & 0.94 & 0 \\
\hline
\end{tabular}


Table 3: Summary of NAP6 results regarding NMBAs ${ }^{2,22,26}$

\begin{tabular}{|c|c|c|c|c|c|c|c|}
\hline NMBA & $\begin{array}{l}\text { Estimated no } \\
\text { of patients } \\
\text { receiving NMBA } \\
\text { per annum }\end{array}$ & $\begin{array}{l}\% \text { of } \\
\text { all GA } \\
\text { cases }\end{array}$ & $\begin{array}{l}\% \text { of all cases } \\
\text { receiving } \\
\text { NMBA }\end{array}$ & $\begin{array}{l}\text { No of cases of } \\
\text { anaphylaxis }\end{array}$ & $\begin{array}{c}\% \text { of total } \\
\text { anaphylaxis } \\
\text { cases with } \\
\text { identified cause }\end{array}$ & $\begin{array}{l}\text { Rate of anaphylaxis } \\
\text { (per } 100000 \\
\text { administrations) }\end{array}$ & $\begin{array}{l}\text { No of deaths } \\
\text { due to NMBA }\end{array}$ \\
\hline All NMBAs & 1129478 & $47.2 \%$ & $100 \%$ & 64 & $33 \%$ & Not determined & 4 \\
\hline Rocuronium & 459047 & $19.2 \%$ & $40.6 \%$ & 27 & $13.5 \%$ & 5.88 & 3 \\
\hline Succinylcholine & 126086 & $5.3 \%$ & $11.2 \%$ & 14 & $7.0 \%$ & 11.1 & 1 \\
\hline Atracurium & 554543 & $23.2 \%$ & $49.1 \%$ & 23 & $11.6 \%$ & 4.15 & 0 \\
\hline Mivacurium & 30786 & $1.3 \%$ & $2.7 \%$ & 1 & $0.5 \%$ & 3.25 & 0 \\
\hline
\end{tabular}

in NAP6

where cephalosporins are used more frequently, such as in the US, have identified them as a significant cause of perioperative anaphylaxis. ${ }^{25,29}$

\section{NMBAs}

Although previous studies in France placed NMBAs as the most likely to cause perioperative anaphylaxis, ${ }^{24}$ in the NAP6 survey they were the second most likely cause as a drug group. Sixty-four out of the 192 identifiable causes of perioperative anaphylaxis cases were attributed to a NMBA (33\% of all cases). The most commonly implicated agents were rocuronium, atracurium and succinylcholine. An overview of the results relating to NMBAs is given in Table 3.

Succinylcholine was found to cause 11 cases of anaphylaxis, but was more than two times as likely to cause it as compared to rocuronium ( 11.1:100 000 administrations). This was because succinylcholine represented only $10 \%$ of all NMBA use in anaesthesia. Rocuronium and atracurium were identified as the cause in 27 and 23 cases respectively, but these two agents also represented $83 \%$ of all NMBA use. Their relative risk of anaphylaxis was therefore determined to much lower than that of succinylcholine. ${ }^{2}$

No cases of anaphylaxis from cisatracurium, pancuronium or vecuronium were identified, but the Allergen Survey showed that these three agents collectively represent $<5 \%$ of total NMBA use by anaesthetist annually. ${ }^{22}$ In other studies, all these agents have been implicated at one time or another to cause anaphylaxis. ${ }^{24}$

Importantly, of the patients that tested positive for NMBA allergy who then had a NMBA cross-reactivity panel performed, 17 were found to be cross-reactive even to NMBAs outside the trigger agent's structural class. This translated to a crude $40 \%$ cross- reactivity rate. The implications of this are crucial. If an NMBA in a particular case is identified as an anaphylactic trigger, a 'safe' paralytic option still needs to be formally identified through allergen testing and not through empiric rationale based on chemical structure and class. In a single case during NAP6, rocuronium and succinylcholine were found to be equally likely to have triggered anaphylaxis, exemplifying well this purported cross-reactivity. ${ }^{2}$

\section{Other Triggers}

Chlorhexidine was identified as the third most common cause of perioperative anaphylaxis in NAP6. ${ }^{2}$ It has been noted to be a potent emerging cause of hypersensitivity. ${ }^{30}$ In the perioperative setting it may be found in coated central-venous catheters, lubricating gels, skin disinfectants, mouth wash and dental implants. ${ }^{31}$ Chlorhexidine presented with delayed ( 1 hour post exposure) anaphylaxis as compared to other causes, except when chlorhexidine-coated central venous catheters were used. In these instances, initial signs were noted within five minutes. ${ }^{2}$

Patent Blue, a dye used for intraoperative lymph node mapping, was the fourth most frequent cause, associated with 9 cases, with a relatively high incidence compared to the other drugs of 14.6 per 100000 administrations. This is notably higher risk than succinylcholine, albeit lower than teicoplanin. ${ }^{2}$

Latex did not feature in a single case from NAP6. In previous studies in France, it had been the second most frequent cause in a retrospective review spanning 9 years. ${ }^{24}$ However, latexrelated anaphylaxis had already been noted to be declining in more recent studies, ${ }^{3}$ likely as a result of diminishing latex use in healthcare.

Table 4: Infrequent Perioperative Anaphylaxis Triggers Identified in NAP6 and Other Studies

\begin{tabular}{ll}
\hline Other causes identified in NAP6 (no of cases) ${ }^{\mathbf{2}}$ & Other causes in older studies $^{\mathbf{2 3 , 2 4 , 2 5}}$ (not found in NAP6) $^{\text {(n) }}$ \\
\hline Colloids (3 cases) - gelatin colloids only & Latex \\
Ondansetron (2) & Colloids - Hetastarch, Albumin \\
Propofol (1) & Hypnotics - Midazolam, Thiopental, Ketamine \\
Ibuprofen (1) & Non-opiate Analgesics - Propacetamol, Paracetamol, Nefopam \\
Protamine (1) & Opioids - Morphine, Fentanyl, Sufentanil, Nalbuphine, Remifentanil \\
Aprotinin (1) & Local Anaesthetics - Bupivacaine, Lignocaine, Mepivacaine, Prilocaine \\
Heparin (1) & Povidone lodine \\
Blood Products (2) - cryoprecipitate, fresh frozen plasma & Surgical Dyes - Methylene Blue, Isosulfan Blue \\
& Ranitidine \\
\hline
\end{tabular}


Other rare but identified causes are briefly mentioned in Table 4. This is by no means a complete list of all reported causes. Rather, it should alert the clinician that many different agents - both frequently and infrequently encountered - carry an anaphylactic risk.

What is clear from the collective sum of this epidemiological data is that there is a significant geographical variation in the main causal agents involved. Triggers in a LMIC or African setting are unknown. Given the preponderance of allergic disease in the developed as compared to the developing world, it would be reasonable to assume our incidence might be lower. This remains conjecture, unfortunately. Until data from South Africa or at least other African or LMIC countries becomes available, NAP6 will remain the best source for determining anaphylactic risk of particular drugs.

\section{Clinical Presentation}

No studies examining anaesthetists' knowledge of the clinical presentation of perioperative anaphylaxis could be found. From the author's personal interactions, most if not all colleagues assume a combination at least two of lower respiratory tract, upper respiratory tract, cutaneous or cardiovascular signs following drug administration is necessary to clinically demonstrate anaphylaxis. Despite being described more than 100 years ago, until relatively recently anaphylaxis lacked a clear definition, leading to many misconceptions. ${ }^{32}$

\section{Diagnostic Criteria}

Local criteria, established by the Resuscitation Council of South Africa (RCSA) and endorsed by the Allergy Society of South Africa (ALLSA), are shown in Figure 2.

\section{ACUTE RESPIRATORY DIFFICULTY \\ (Progressive Swelling, Stridor, Wheezing, Distress) and/or \\ SIGNS OF SHOCK/HYPOTENSION}

(especially if skin or mucosal changes are present)

Figure 2: Resuscitation Council of South Africa ${ }^{33}$

Anaphylaxis Diagnostic Criteria
These criteria, whilst broad enough for an emergency department or pre-hospital setting, are perhaps too broad for the perioperative setting. The other major causes of anaphylaxis, namely food allergies and insect stings, have a far greater relative propensity to cause respiratory symptoms and skin changes. ${ }^{34}$ We know from NAP6 and many previous studies that this is not the case for perioperative anaphylaxis, where hypotension and cardiovascular compromise seems to be a universal and often initial finding. Reliance on respiratory or cutaneous signs may therefore lead to late or mis-diagnosis., ${ }^{2,34}$

In 2011, the World Allergy Organisation (WAO) and its 84 member organisations endorsed new criteria for the diagnosis of anaphylaxis, which were originally published in 2006 by Sampson et al. ${ }^{34}$ This set of criteria identified three sets of conditions (shown in Table 5), each of which is sufficient to identify anaphylaxis.

This more comprehensive set of criteria acknowledges the variety of ways in which anaphylaxis may present. The third set of criteria is particularly relevant to anaesthetic practice. There is increased recognition that hypotension in isolation can represent anaphylaxis in a significant proportion of cases. The inclusion 'known allergen' in the case definition is meant to allow discrimination from other causes. In anaesthetic practice, given the lack of definitive allergy testing prior to surgery, we need to acknowledge that definitive diagnosis may have to be retrospective. If cardiovascular collapse is noted after a potential allergen has been administered, it may be reasonable to treat the episode as 'presumed' anaphylaxis.

\section{Grading}

No universal consensus exists regarding grading of anaphylaxis severity. There is equipoise whether mild hypersensitivity reactions, even those involving multiple systems, should be considered anaphylaxis at all. ${ }^{2}$

Furthermore, most of the grading systems developed are not specific for perioperative anaphylaxis. Rose et al. developed a perioperative anaphylaxis grading system in 2016, with three degrees of severity. ${ }^{35}$ The NAP6 investigators concurrently developed a 5 scale grading system, shown in Table $6 .{ }^{15}$ Cases

Table 5: Clinical Criteria for Diagnosing Anaphylaxis adapted from 34

\section{Anaphylaxis is highly likely when any one of the following $\mathbf{3}$ criteria is fulfilled:}

\section{Acute onset (minutes to several hours) of an illness With mucocutaneous involvement \\ AND AT LEAST ONE OF THE FOLLOWING \\ a. Respiratory compromise \\ b. Cardiovascular compromise \\ 2 Acute onset AFTER exposure to a likely allergen for that patient \\ WITH TWO OR MORE of the following \\ a. Mucocutaneous involvement \\ b. Respiratory compromise \\ c. Cardiovascular compromise \\ d. Persistent Gl involvement}

Examples of features

$\rightarrow$ generalised hives, itch, flushing, swollen lips-tongue-uvula

$\rightarrow$ dyspnea, wheeze-bronchospasm, stridor, $\downarrow$ PEF, hypoxaemia

$\rightarrow$ reduced $\mathrm{BP}$, hypotonia, collapse, syncope, incontinence

3 Acute reduction in blood pressure AFTER exposure to known allergen for that patient

\author{
$\rightarrow$ generalised hives, itch, flushing, swollen lips-tongue-uvula \\ $\rightarrow$ dyspnea, wheeze-bronchospasm, stridor, $\downarrow$ PEF, hypoxemia \\ $\rightarrow$ reduced $B P$, hypotonia, collapse, syncope, incontinence \\ $\rightarrow$ crampy abdominal pain, vomiting \\ nfants/children $\rightarrow$ low SBP (age specific) or $\geq 30 \%$ decrease in SBP \\ Adults $\rightarrow$ SBP $<90 \mathrm{~mm} \mathrm{Hg}$ or $\geq 30 \%$ decrease from baseline
}

$\mathrm{BP}=$ Blood Pressure; PEF = Peak Expiratory Flow Rate; GI = Gastrointestinal; SBP = Systolic BP 
Table 6: NAP6 Perioperative Hypersensitivity/Anaphylaxis Grading System ${ }^{15}$

\begin{tabular}{|c|c|c|c|}
\hline Grade & Features & NAP6 & $\begin{array}{l}\text { Perioperative Anaphylaxis Grading } \\
\text { System }^{35} \text { Equivalent }\end{array}$ \\
\hline 1 & Rash, erythema or swelling & No & Not included \\
\hline 2 & $\begin{array}{l}\text { Unexpected hypotension } \\
\text { - not severe, e.g. not requiring treatment and/or bronchospasm } \\
\text { - not severe, e.g. not requiring treatment }+/ \text { - Grade } 1 \text { features }\end{array}$ & No & Grade A - Moderate \\
\hline 3 & $\begin{array}{l}\text { Unexpected severe hypotension and/or severe bronchospasm and/or swelling } \\
\text { with actual/potential airway compromise +/- Grade } 1 \text { features }\end{array}$ & Yes & Grade B - Severe \\
\hline 4 & Fulfilling indications for CPR including systolic blood pressure $<50 \mathrm{mmHg}$ & Yes & Grade C - Cardiac/respiratory arrest \\
\hline 5 & Fatal & Yes & Grade C - Cardiac/respiratory arrest \\
\hline
\end{tabular}

of perioperative hypersensitivity that were deemed as not life-threatening (Grade 1 and 2) were not included in NAP6 as perioperative anaphylaxis cases.

\section{Clinical Presentation}

Drug-induced anaphylaxis has been noted to present differently from food or insect-sting related anaphylaxis. ${ }^{34}$ NAP6 dedicated significant efforts in detailing the incidence and progression of perioperative anaphylaxis. The salient details included the following:

\section{Regarding clinical features:}

- hypotension was universally present in all cases of perioperative anaphylaxis, and was the presenting feature in just under half of cases;

- bronchospasm /high airway pressures was present in roughly half of cases and was the presenting feature in just under 1 in 5 cases;

- urticaria and related rashes were uncommon, and often presented late in the course of the event, often after cardiac arrest or profound hypotension had mandated resuscitation;

- upper airway features (angioedema) were seen very rarely, and only 1 case out of 266 required front-of-neck access;

- hypotension and bronchospasm were the most common features associated with fatalities.

Regarding the time course:

- the first clinical feature appeared within 5 minutes in two thirds of cases, and within 10 minutes in $83 \%$ of cases;

- most cardiac arrests occurred shortly after initial features were noted:
- a delay of more than 30 minutes from exposure to onset of first feature was rare, occurring in less than $5 \%$ of cases, mostly as a result of non-intravenous allergen administration (e.g. chlorhexidine, Patent Blue).

In contrast, food and insect-venom related anaphylaxis tends to present with a greater incidence of 'asthma-like' and upperairway symptoms than drug-induced perioperative anaphylaxis. These also tend to be more delayed, leading to cardiac arrest much later after onset - a median of 30 minutes for food and 15 minutes for venom-induced anaphylaxis. ${ }^{36}$ It is perhaps then understandable that many clinicians presume that anaphylaxis is not the likely precipitant in events lacking these features and natural history.

The NAP6 findings should challenge the notion that anaphylaxis mandates a constellation of symptoms. Given the plethora of reasons for early intraoperative hypotension to develop, ${ }^{37}$ it is not surprising that anaphylaxis is perhaps not at the forefront, given its relative rarity. Nevertheless, initial presentation of hypotension in the early perioperative period should, in isolation, warrant a reflection on whether this is the first feature of anaphylaxis, particularly if hypotension is refractory to regular therapy.

\section{Management}

Numerous protocols exist for the management of anaphylaxis, most notably South African guidelines ${ }^{33}$ and the World Allergy Organisation guidelines, ${ }^{18}$ though neither of these is specific for the perioperative setting. Perioperative guidelines have been published by various anaesthesia societies, including the UK, ${ }^{38}$ Australia ${ }^{39}$ and Scandinavian ${ }^{40}$ nations. Though not reproduced here, they all share certain characteristics - adrenaline use,

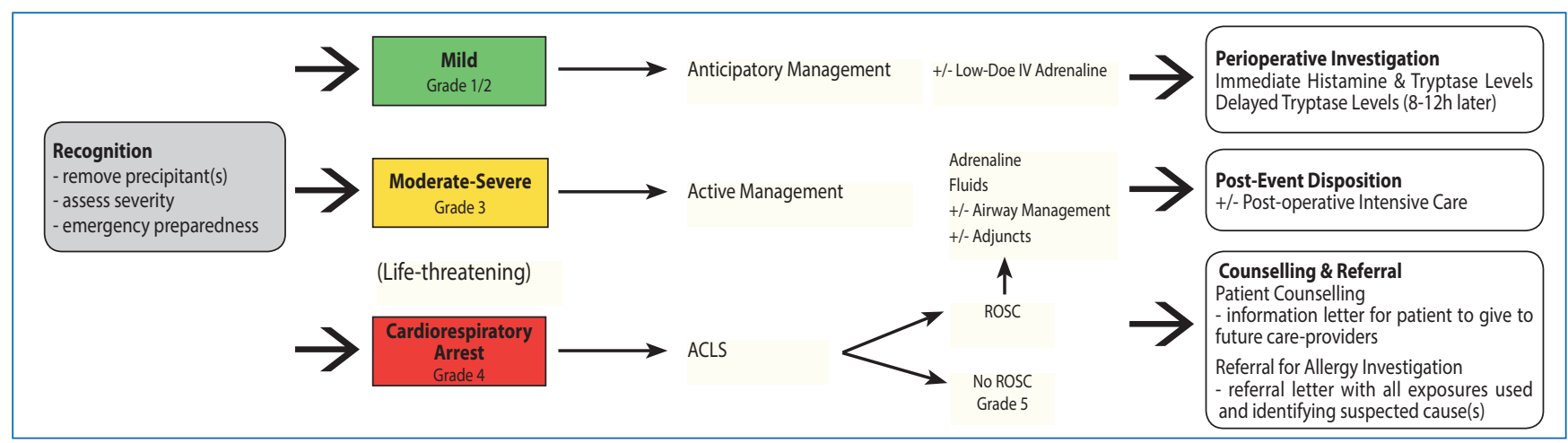

Figure 3: Overview of Management 
fluid administration, variable adjunct use and appropriate investigation and follow-up. A simplification of key aspects in these guidelines is shown in Figure 3, and addressed in more detail below.

\section{Recognition}

The need for prompt recognition should be obvious. Given the myriad ways anaphylaxis may present, it is likely many cases are missed or unreported. A renewed focus on seeking underlying causes of unexplained hypotension, alongside a clearer understanding of the natural history of perioperative anaphylaxis, should aid the practising anaesthetist in identifying otherwise 'missable' cases.

\section{Cardiac Arrest and Life Support}

When anaphylaxis is considered a potential cause of severe unexplained hypotension, treatment should be instituted immediately. Little is to be gained and much lost with any delays in treatment, as progression to cardiac arrest might be swift if adrenaline and fluids are withheld. Unfortunately, cardiac arrest is occasionally the first feature noted, in which case Advanced Cardiac Life Support cardiopulmonary resuscitation algorithms should be followed.

Cardiac arrest occurred in 40 out of the 266 patients in the NAP6 survey, with PEA being the predominant initial rhythm. Return of spontaneous circulation was achieved in 32 of those with cardiac arrest, with 8 fatal cases. Two further cases demised in the postoperative period. This equates to an incidence of perioperative death from anaphylaxis of 1 in 239000 general anaesthetics and 1 in 313000 anaesthetic interventions. Of all cases of lifethreatening (Grade3+) perioperative anaphylaxis, 3.8\% (1 in 26.6) died. ${ }^{2}$

\section{Pharmacological Management}

There are few studies of the efficacy of individual drugs in the management of perioperative anaphylaxis, and no randomised clinical trials (RCTs), as a result of which the majority of published information derives from case reports and retrospective analyses.

\section{Adrenaline}

Early administration of adrenaline is associated with improved outcomes in out-of-hospital anaphylaxis. ${ }^{34}$ There is little doubt that adrenaline is the drug of choice in treating anaphylaxis, but a reluctance to administer adrenaline has noted. ${ }^{41}$ Delay in administering adrenaline is associated with worse outcomes in outpatient settings..$^{34,36}$

Intraoperative dosing remains an evolving area and has resulted in some controversy. The dose of adrenaline in outpatient presentations of anaphylaxis is $0.3-0.5 \mathrm{mg}$ IMI (anterolateral thigh) or $0.01 \mathrm{mg} / \mathrm{kg}$ in the paediatric population, repeated every 5 minutes until symptoms improve. ${ }^{33}$ However, these recommendations are made cognisant of the fact that patients presenting with anaphylaxis outside of the theatre environment rarely present with intravenous access or continuous monitoring. In the perioperative setting, IV access is almost universally established prior to administering most medications. Several guidelines make reference to using intravenous adrenaline as the initial treatment, with early establishment of an adrenaline infusion. Their recommendations are summarised in Table 7. Initial administration of intramuscular adrenaline is reasonable whilst appropriate doses for IV or infusions are prepared.

The NAP6 survey found that those patients not requiring CPR tended to be managed less well, and were ironically more likely to come to harm than those who did. ${ }^{2}$ This potentially reflects the reluctance to give adrenaline in these cases, whereas adrenaline was universally administered if cardiac arrest occurred as part of ACLS efforts.

\section{Fluid Management}

The profound vasodilation, increased permeability and fluid sequestration that is central to anaphylaxis pathophysiology, results in significant decreases in venous return and cardiac output and contributed to the development of cardiac arrest. Liberal IV fluids are part of every guideline, usually $20 \mathrm{ml} / \mathrm{kg}$ boluses of a balanced crystalloid, repeated as necessary. ${ }^{33,39}$

Stop colloids if already being administered as they may be the underlying trigger. Consider their use for volume expansion, if not already being used and therefore an unlikely trigger.

\section{Adjuncts}

A plethora of adjuncts has been advocated for use in anaphylaxis. Their use is not evidence based, but rather extrapolated from physiological principles based on knowledge of similar disease processes (e.g. salbutamol for asthmatics, antihistamines for urticaria). Retrospective studies examining their use have not shown demonstrable harm or benefit in the presence of adrenaline co-administration, and most protocols recommend

Table 7: Summary of Adrenaline Dosing Guidelines for Perioperative Anaphylaxis

\begin{tabular}{|c|c|c|}
\hline Guideline Origin & Adult Dosing & Paediatric Dosing \\
\hline $\mathrm{UK}^{38}$ & $\begin{array}{l}50 \mu \mathrm{g} \text { bolus IV, } \\
\text { repeat as necessary } \\
\text { Infusion if several doses required }\end{array}$ & $\begin{array}{l}1 \mu \mathrm{g} / \mathrm{kg} \text { bolus IV, } \\
\quad \text { repeat as necessary } \\
\text { Infusion if several doses required }\end{array}$ \\
\hline Scandinavian Countries ${ }^{40}$ & $\begin{array}{l}\text { Mild to moderate reaction: } 0.01-0.05 \mathrm{mg} \text { IV } \\
\text { Circulatory collapse: } 0.1-1.0 \mathrm{mg} \text { IV } \\
\text { Infusion starting at: } 0.05-0.1 \mathrm{mg} / \mathrm{kg} / \mathrm{min} \\
\text { Without IV access } \rightarrow 0.5-0.8 \mathrm{mg} \text { i.m. }\end{array}$ & $\begin{array}{l}\text { Mild to moderate reaction: } 1-5 \mu \mathrm{g} / \mathrm{kg} \text { IV } \\
\text { Circulatory collapse: } 10 \mu \mathrm{g} / \mathrm{kg} \text { IV } \\
\text { Without IV access: } 5-10 \mu \mathrm{g} / \mathrm{kg} \text { IM }\end{array}$ \\
\hline Australia ${ }^{39}$ & $\begin{array}{l}\text { Moderate reaction: } 20 \mu \mathrm{g} \text { IV bolus } \\
\text { Life-threatening reaction: } 100-200 \mu \mathrm{g} \text { bolus } \\
\text { Followed by infusion }\end{array}$ & $\begin{array}{l}\text { Moderate reaction: } 2 \mu \mathrm{g} / \mathrm{kg} \text { IV bolus } \\
\text { Life-threatening reaction: } 4-10 \mu \mathrm{g} / \mathrm{kg} \text { bolus } \\
\text { Followed by infusion }\end{array}$ \\
\hline
\end{tabular}


their addition to the anaphylaxis treatment bundle. Their administration should not be prioritised over that of adrenaline, however. Certain agents are reserved for use in instances of anaphylaxis refractory to adrenaline.

Some adjuncts and their recommended doses are summarised in Table 8 below.

\section{Airway management}

NAP6 showed a low incidence of upper airway features in perioperative anaphylaxis, with only one instance in which airway management progressed to the need for a surgical airway. ${ }^{2}$ Airway management should not be prioritised over adrenaline administration unless airway obstruction or respiratory failure is anticipated.

The role of anaesthetists in managing difficult airways means that any practitioner may be called to assist out of theatre, for instance in the case a patient presenting with angioedema or bronchospasm in an emergency department. In this instance the anaesthetist should assess a patient as a potential anaphylaxis and institute appropriate management (adrenaline) prior to airway instrumentation, if this is deemed a potential cause. Furthermore, the risk of failure to secure a non-surgical airway is high in these instances due to airway oedema. Care should be taken to ensure difficult airway algorithms are followed, and surgical airway access attempted timeously.

\section{Investigation}

Although resuscitation efforts and treatment of the disease process should dominate early care efforts, attempts at confirmation of anaphylaxis as the cause should proceed once a patient is stabilised. Unfortunately, allergy services are still nascent in most parts of Africa, so this may not always be possible. Regardless, one should be cognisant of recommendations for the following tests in the perioperative period. ${ }^{42}$

Immediate Blood Samples - Histamine and Tryptase

Delayed (base-line) Blood Samples - Tryptase - taken 8-12hours later

\section{Post-resuscitative Care}

Many patients can have prolonged inotropic or vasopressor requirements. There is also the risk of a recurrence of symptoms 1-72 hours after the initial episode. ${ }^{18}$ Therefore, the admission of these patients to a high dependency monitored setting is recommended. Standard principles of intensive care apply to these patients.

\section{Counselling and Referral}

Counselling the patient or their family regarding the nature of the event should occur as early as possible and appropriate. This should include a detailed referral to an allergy service if available. Additionally, supplying the patient with a letter detailing the agents used and suspected of causing the event may help colleagues planning a future anaesthetic should they encounter the patient. Given the potentially life-threatening nature of a future event, combined with the paucity of allergy services, this letter may represent the only chance a patient has of avoiding a recurrence during future anaesthetics. Interestingly, the anaesthetists correctly guessed the causative agent in three quarters of cases referred to allergy services during NAP6. ${ }^{2}$

\section{Conclusion}

Knowledge of and training in the recognition, diagnosis and management of anaphylaxis should be part of the core training of anaesthetists and other theatre and recovery room personnel. This training should particularly emphasise what we now know about how perioperative anaphylaxis presents, namely hypotension and/or bronchospasm. Additionally, the early administration of adrenaline at appropriate doses should be emphasised, particularly in lieu of other treatments known to be less effective. ${ }^{2}$

Common sense recommendations given what we now know about how anaphylaxis presents should be borne in mind. Consider anaphylaxis as a potential cause of hypotension and/or cardiac arrest. Give antibiotics early in the course of an anaesthetic, preferably several minutes prior to the administration of a neuraxial or general anaesthetic. Other

Table 8: Adjuncts Recommended by Perioperative Anaphylaxis Guidelines $38,39,40$

\begin{tabular}{|c|c|c|c|c|}
\hline Drug Group & Specific Agent & Adult Dose & Paediatric Dose & Specific Indication \\
\hline Corticosteroids & $\begin{array}{l}\text { Hydrocortisone } \\
\text { Methylprednisone }\end{array}$ & $\begin{array}{c}200-250 \mathrm{mg} \text { IV } \\
80 \mathrm{mg} \text { IV }\end{array}$ & $\begin{array}{l}50-100 \mathrm{mg} \text { IV } \\
2 \mathrm{mg} / \mathrm{kg} \mathrm{IV}\end{array}$ & Only use one \\
\hline $\mathrm{H} 1$ Antihistamines & $\begin{array}{c}\text { Clemastin } \\
\text { Chlorpheniramine } \\
\text { Promethazine }\end{array}$ & $\begin{array}{l}2 \mathrm{mg} \text { IV } \\
10 \mathrm{mg} \text { IV } \\
50 \mathrm{mg} \text { IV }\end{array}$ & $\begin{array}{c}0.0125-0.025 \mathrm{mg} / \mathrm{kg} \\
5 \mathrm{mg} \mathrm{IV} \\
0.3-1.0 \mathrm{mg} / \mathrm{kg} \mathrm{IV}\end{array}$ & Only use one \\
\hline $\mathrm{H} 2$ Antihistamine & Ranitidine & $50 \mathrm{mg}$ IV & Not recommended & \\
\hline$\beta 2$ Agonists & Salbutamol & $\begin{array}{c}\text { Nebulised OR } \\
100-200 \mu \mathrm{g} \text { bolus } \\
5-25 \mu \mathrm{g} / \mathrm{min} \text { infusion }\end{array}$ & $\begin{array}{l}\text { Nebulised OR } \\
\text { infusion }\end{array}$ & Bronchospasm \\
\hline Vasopressors & $\begin{array}{l}\text { Noradrenaline } \\
\text { Vasopressin Metaraminol } \\
\text { Phenylephrine }\end{array}$ & $\begin{array}{c}0.05-0.5 \mu \mathrm{g} / \mathrm{kg} / \mathrm{min} \\
2-10 \mathrm{IU} \text { IV }+/ \text { - infusion } \\
\text { infusion } \\
\text { infusion }\end{array}$ & $0.05-2 \mu \mathrm{g} / \mathrm{kg} / \mathrm{min}$ & $\begin{array}{l}\text { Refractory } \\
\text { Refractory } \\
\text { Refractory } \\
\text { Refractory }\end{array}$ \\
\hline Other & Glucagon & $1-2$ mg IV increments & & $\beta$-blocker use \\
\hline
\end{tabular}


similar recommendations are made in Chapter 2 of NAP6, and warrant independent reading.

To continue to improve quality of care, we need to better our understanding of how anaesthesia is practised in the South African setting. Extrapolation from international data will always have limitations. The need for a NAP-like study in LMIC has been discussed and established in the SAJAA previously by Kluts et al. ${ }^{14}$ Initiatives such as this should be sought to explore our own experience with perioperative anaphylaxis.

Finally, remember that although the appropriate intraoperative recognition and management of anaphylaxis is our ethical duty given our causal role, the perioperative period is not the only situation in which South African anaesthetists are likely to encounter anaphylaxis. Airway management can be delegated to us by our colleagues working in emergency departments or inpatient wards, and recognition of the event as anaphylaxis can alter the clinical course dramatically. Likewise, given the scarcity of health professionals in South Africa, it would not be unheard of a family member, friend or neighbour approaching an individual anaesthetist for advice regarding a sudden rash, facial swelling or new onset dizziness that may indicate anaphylaxis. Appropriate and informed management of anaphylaxis in all settings therefore becomes our duty, particularly given the potentially precipitous life-threatening but ultimately reversible nature of the disease process.

\section{References}

1. Johansson SG, Bieber T, Dahl R, et al. Revised nomenclature for allergy for global use: Report of the Nomenclature Review Committee of the World Allergy Organization, October 2003. J Allergy Clin Immunol. 2003;113:832-6.

2. Cook TM, Harper N. Anaesthesia, Surgery and Life-Threatening Allergic Reactions: Report and findings of the Royal College of Anaesthetists' 6th National Audit Project: Perioperative Anaphylaxis. Br J Anaesth in press. 2018.

3. Mertes PM, Volcheck GW, Garvey LH, et al. Epidemiology of perioperative anaphylaxis. Presse Med. 2016;45:758-67.

4. Fleisher LE, Rosenbaum SH, eds. Complications in Anesthesia, 3rd ed. Philadephia: Elsevier; 2017.

5. Cook TM, Woodall N, Frerk C. $4^{\text {th }}$ National Audit Project. Major complications of airway management in the UK: results of the 4th National Audit Project of the Royal College of Anaesthetists and the Difficult Airway Society, Part 1: anaesthesia. Br J Anaesth. 2011;106:617-31.

6. Mertes PM, Tajima K, Regnier-Kimmoun MA, et al. Perioperative anaphylaxis. Med Clin N Am. 2010;94:761-89.

7. Gibbs NM, Sadleir PH, Clarke RC, Platt PR. Survival from perioperative anaphylaxis in Western Australia 2000-2009. Br J Anaesth. 2013;111:589-93.

8. Reitter $\mathrm{M}$, Petitpain $\mathrm{N}$, Latarche $\mathrm{C}$, et al. Fatal anaphylaxis with neuromuscular blocking agents: a risk factor and management analysis. Allergy. 2014;69:954-9.

9. Trautmann A, Seidl C, Stoevesandt J, Seitz CS. General anaesthesia-induced anaphylaxis: impact of allergy testing on subsequent anaesthesia. Clin Exp Allergy. 2016;46:125-32.

10. Turner PJ, Campbell DE. Epidemiology of severe anaphylaxis: can we use population-based data to understand anaphylaxis? Curr Opin Allergy Clin Immunol. Oct 2016;16(5):441-50.

11. Gibbison B, Sheikh A, McShane P, Haddow C, Soar J. Anaphylaxis admissions to UK critical care units between 2005 and 2009. Anaesthesia. 2012;67:833-9.

12. Cook TM, Thomas $G$. The United Kingdom National Audit Projects: a narrative review. South Afr J Anaesth Analg. 2016;22(2):38-45.

13. Dippenaar JM, Naidoo S. Allergic Reactions and Anaphylaxis During Anaesthesia. Current Allergy \& Clinical Immunology. 2015;28(1):18-22.

14. Kluyts HL, Hofmeyr R, Biccard BM. The United Kingdom National Audit Project Program - an opportunity for South Africa? South Afr J Anaesth Analg. 2016;22(2):4.
15. Cook TM, Harper NJN, Farmer L, et al. Anaesthesia, surgery, and life-threatening allergic reactions: protocol and methods of the 6th National Audit Project (NAP6) of the Royal College of Anaesthetists. Br J Anaesth in press. 2018.

16. Morgan GE, Mikhail MS, Murray MJ, eds. Clinical Anaesthesiology, $3^{\text {rd }}$ Edition, New York: McGraw-Hill; 2001

17. Muñoz-Cano R, Pascal M, Araujo $G$, et al. Mechanisms, Cofactors, and Augmenting Factors Involved in Anaphylaxis. Front Immunol. 2017;8:1193.

18. Simons FER, Ardusso LRF, Bilo MB, et al. World Allergy Organization Guidelines for the Assessment and Management of Anaphylaxis. J Allergy Clin Immunol. 2011;127:593 e1-e22.

19. Takahashi K, Suzuki H, Arai T, Okuda Y. Morphine-induced Anaphylaxis before Induction of Anesthesia. Masui. Apr 2016;65(4):363-5.

20. Volcheck GW, Mertes PM. Local and general anesthetics immediate hypersensitivity reactions. Immunol Allergy Clin N Am. 2014:34;525-46.

21. Turner PJ, Jerschow E, Umasunthar T, Lin R, Campbell DE, Boyle RJ. Fatal Anaphylaxis: Mortality Rate and Risk Factors. J Allergy Clin Immunol Pract. 2017;5:1169-78.

22. Marinho $\mathrm{S}$, Kemp H, Cook TM et al. A cross sectional study of Perioperative drug and allergen exposure in United Kingdom practice in 2016: the 6th National Audit Project (NAP6) Allergen Survey. Br J Anaesth in press. 2018.

23. Low AE, McEwan JC, Karanam S, North J, Kong KL. Anaesthesia-associated hypersensitivity reactions: Seven years' data from a British bi-specialty clinic. Anaesthesia. 2016;71:76-84.

24. Mertes PM, Alla F, Trechot $P$, et al. Anaphylaxis during anesthesia in France: An 8-year national survey. J Allergy Clin Immunol. 2011;128:366-73.

25. Gurrieri C, Weingarten TN, Martin DP, et al. Allergic reactions during anesthesia at a large United States referral center. Anesth Analg. 2011:113;1202-12.

26. Kemp H, Marinho S, Cook TM, et al. An observational national study of anaesthetic workload and seniority across the working week and weekend in the United Kingdom in 2016: The 6th National Audit Project (NAP6) Activity Survey. Br J Anaesth in press. 2018.

27. Steinke JW, Rich SS, Borish L. Genetics of allergic disease. J Allergy Clin Immunol. Feb 2008;121(2 Suppl):S384-7.

28. Joint Task Force on Practice Parameters, Solensky R, Khan DA, Bernstein IL, et al. Drug allergy: an updated practice parameter. Ann Allergy Asthma Immunol. Oct 2010;105(4):259-73.

29. Kuhlen JL Jr, Camargo CA Jr, Balekian DS, et al. Antibiotics Are the Most Commonly Identified Cause of Perioperative Hypersensitivity Reactions. J Allergy Clin Immunol Pract. 2016:4;697-704.

30. Egner W, Helbert M, Sargur R, et al. Chlorhexidine allergy in four specialist allergy centres in the United Kingdom, 2009-13: clinical features and diagnostic tests. J Clin Exp Immunol. 2017;188:380-6.

31. Krishna MT, Huissoon A. Peri-Operative Anaphylaxis: Beyond Drugs and Latex. Int Arch Allergy Immunol. 2015;167:101-2.

32. Sampson HA, Munoz-Furlong A, Campbell RL et al. Second symposium on the definition and management of anaphylaxis: summary report - Second National Institute of Allergy and Infectious Disease/Food Allergy and Anaphylaxis Network symposium. J Allergy Clin Immunol. 2006;117:391-7.

33. Resuscitation Council of Southern Africa. Anaphylaxis Management - Adult \& Child. Published online 2015. Available from: http://www.resus.co.za/

34. Pumphrey RSH. Lessons for management of anaphylaxis from a study of fatal reactions. J Clin Exp Allergy. 2000;30:1144-50.

35. Rose MA, Green SL, Crilly HM, Kolawole H. Perioperative anaphylaxis grading system:' 'making the grade'. Br J Anaesth. 2016;117:551-3.

36. Pumphrey RS, Roberts IS. Postmortem findings after fatal anaphylactic reactions. J Clin Pathol. 2000;53:273-6.

37. Reich 2005: Reich DL, Hossain S, Krol M, et al. Predictors of hypotension after induction of general anesthesia. Anesth Analg. 2005;101:622-8.

38. Harper NJN, Dixon T, Dugué $P$, et al. Guidelines suspected anaphylactic reactions associated with anaesthesia. Anaesthesia. 2009;64:199-211.

39. Scolaro RJ, Crilly HM, Maycock EJ, et al. Australian and New Zealand Anaesthetic Allergy Group Perioperative Anaphylaxis Investigation Guidelines. Anaesth Intensive Care Australia. 2017;45:543-55.

40. Krøigaard M, Garvey LH, Gillberg L, et al. Scandinavian Clinical Practice Guidelines on the diagnosis, management and follow-up of anaphylaxis during anaesthesia. Acta Anaesthesiol Scand. 2007;51:655-70.

41. Garvey LH, Belhage B, Krøigaard M, Husum B, Malling HJ, Mosbech H. Treatment with epinephrine (adrenaline) in suspected anaphylaxis during anesthesia in Denmark. Anesthesiology 2011;115:111-6.

42. Tacquard C, Laroche D, Stenger R, et al. Diagnostic procedure after an immediate hypersensitivity reaction in the operating room. Presse Med. 2016; 45:784-90. 